\title{
Detection and comparative analysis of persistent measles virus infection in Crohn's disease by immunogold electron microscopy
}

Peter Daszak, Matthew Purcell, Jackie Lewin, Amar P Dhillon, Roy E Pounder, Andrew J Wakefield

\begin{abstract}
Aims-To determine the specificity of persistent measles virus infection in intestinal samples from Crohn's disease patients using quantitative immunogold electron microscopy. To compare the results with samples from ulcerative colitis, a granulomatous inflammatory control (tuberculous lymphadenitis), and a positive control.
\end{abstract}

Methods-Formalin fixed, paraffin embedded intestinal tissue from patients with Crohn's disease was reprocessed and stained with antimeasles nucleocaspid protein primary antibody followed by $10 \mathrm{~nm}$ gold conjugated secondary antibody. Tissue samples were taken from granulomatous and non-granulomatous areas of the intestine. Intestinal samples from patients with ulcerative colitis, tuberculous lymphadenitis, or acute mesenteric ischaemia were similarly processed. Brain tissue from a patient with subacute sclerosing panencephalitis (SSPE) was used as the positive control. Duplicate sections of all tissues were processed without the primary antibody. Stained specimens were examined by electron microscopy.

Results-In Crohn's disease patients, 8/9 foci of granulomatous inflammation and $0 / 4$ foci of non-specific inflammation were positive for measles virus. Of controls, $0 / 5$ non-inflamed intestinal tissues, $1 / 8$ tuberculous tissues, $1 / 5$ ulcerative colitis tissues, and 1/1 SSPE tissues were positive. Gold grain counts per nuclear field-ofview in both Crohn's disease granulomas (43.29) and SSPE (36.94) were significantly higher than in tissues from patients with ulcerative colitis (13.52) or tuberculous lymphadenitis (15.875), and nongranulomatous areas of Crohn's disease (4.89) (p< 0.001, p $<0.001, p=0.0006$, respectively), with no significant difference between Crohn's disease and SSPE $(p>0.1)$. In both SSPE and Crohn's disease staining was confined to a small population of cells exhibiting characteristic cytopathology.

Conclusion-These data support a role for measles virus in the aetiology of Crohn's disease.

(F Clin Pathol 1997;50:299-304)
Keywords: Crohn's disease; ulcerative colitis; inflammatory bowel disease; measles virus; immunogold electron microscopy

Crohn's disease is a chronic inflammatory bowel disease associated with granulomatous vasculitis, ${ }^{1-4}$ suggesting a cellular immune response to antigen within the intestinal microvasculature. Recent evidence, from studies of affected cases ${ }^{56}$ and epidemiological studies of early environmental exposures, ${ }^{7-9}$ have linked persistent measles virus infection of the intestine to Crohn's disease. Recently, a novel protocol for immunogold electron microscopy has been used to identify persistent measles virus infection in both subacute sclerosing panencephalitis (SSPE) and Crohn's disease. ${ }^{10}$ Using quantitative immunogold electron microscopy the present study sought to determine the specificity of persistent measles virus infection comparing intestinal tissue from Crohn's disease; ulcerative colitis, and a granulomatous inflammatory control (tuberculous lymphadenitis). The data were compared with a persistent measles virus infection of the brain (SSPE) as a positive control and non-inflammatory intestinal negative controls taken from cases of acute mesenteric ischaemia. In addition, targeting of granulomatous and non-granulomatous areas in intestinal tissue from the same cases of Crohn's disease allowed testing of the specificity of measles virus for the granuloma in Crohn's disease.

\section{Methods}

SUBJECTS

Paraffin embedded, formalin fixed tissue samples were reprocessed for immunogold electron microscopy from patients with Crohn's disease (resected tissue, 13 patients, mean age 25 years (range 17-56), six females) and ulcerative colitis (five patients, mean age 30 years (range 28-35), three females). Non-inflammatory intestinal controls were tissues from cases of acute mesenteric ischaemia (five patients, mean age 65 years (range 49-90), five females). As a granulomatous control, tissues from cases of tuberculous lymphadenitis, including two cases of ileocaecal disease, were used (eight patients, mean age 34 years (range 23-56), four females). All cases were positive by ZiehlNeelsen staining, culture or both. The measles positive control was a child (age unknown) with SSPE-a persistent measles virus infection of the brain. The diagnosis of Crohn's dis- 
Table 1 Nuclear gold grain count data from tissues examined by immunogold electron microscopy for measles' virus nucleocaspid protein

\begin{tabular}{|c|c|c|c|c|c|c|}
\hline & $\begin{array}{l}\text { Non-inflamed } \\
\text { controls }\end{array}$ & $\begin{array}{l}\text { Ulcerative } \\
\text { colitis }\end{array}$ & Ileocaecal TB & $\begin{array}{l}\text { Crohn's disease } \\
\text { (non-granulomatous } \\
\text { areas targeted) }\end{array}$ & $\begin{array}{l}\text { Crohn's disease } \\
\text { (granulomatous } \\
\text { areas targeted) }\end{array}$ & SSPE \\
\hline $\begin{array}{l}\text { Number of cells } \\
\text { counted }\end{array}$ & 655 & 392 & 299 & 196 & 818 & 228 \\
\hline $\begin{array}{l}\text { Number of } \\
\text { cases }\end{array}$ & 5 & 4 & 8 & 4 & 4 & 1 \\
\hline Maximum & $\begin{array}{l}4.98 \\
(0.044)\end{array}$ & $\begin{array}{l}13.52 \\
(0.120)\end{array}$ & $\begin{array}{l}15.875 \\
(0.141)\end{array}$ & $\begin{array}{l}4.89 \\
(0.043)\end{array}$ & $\begin{array}{l}43.29 \\
(0.385)\end{array}$ & $\begin{array}{l}36.94 \\
(0.328)\end{array}$ \\
\hline Median & 0 & $\begin{array}{l}0.52 \\
\left(4.6 \times 10^{-3}\right)\end{array}$ & 0 & 0 & $\begin{array}{l}0.045 \\
\left(4 \times 10^{-4}\right)\end{array}$ & 0 \\
\hline 75th centile & $\begin{array}{l}0.98 \\
\left(8.7 \times 10^{-3}\right)\end{array}$ & $\begin{array}{l}0.833 \\
\left(7.4 \times 10^{-3}\right)\end{array}$ & $\begin{array}{l}2.075 \\
\left(1.8 \times 10^{-2}\right)\end{array}$ & $\begin{array}{l}0.89 \\
\left(7.9 \times 10^{-3}\right)\end{array}$ & $\begin{array}{l}1.29 \\
\left(1.1 \times 10^{-2}\right)\end{array}$ & $\begin{array}{l}1.94 \\
\left(1.7 \times 10^{-3}\right)\end{array}$ \\
\hline $\begin{array}{l}\text { Interquartile } \\
\text { range }\end{array}$ & $0-0.98$ & $0-0.833$ & $0-2.075$ & $0-0.89$ & $0-1.29$ & $0-1.94$ \\
\hline
\end{tabular}

The number of gold grains per five nuclear fields-of-view are shown (values per $\mu \mathrm{m}^{2}$ ).

TB, tuberculous lymphadenitis; SSPE, subacute sclerosing panencephalitis.

ease or ulcerative colitis was established by standard clinical, radiological, and histopathological criteria.

\section{TARGETING AND REPROCESSING OF PARAFFIN EMBEDDED TISSUE FOR IMMUNOGOLD ELECTRON MICROSCOPY}

Areas of histological interest were selected from the paraffin blocks. These included nine granulomatous foci (three with giant cells) and four non-granulomatous areas of inflamed mucosa in Crohn's disease tissues. Areas of non-specific mucosal inflammation were selected to allow comparison between granulomatous and non-granulomatous areas within the same specimens. From ulcerative colitis tissues, three foci of inflamed and two of non-inflamed mucosa were selected. Eight areas were selected from non-inflamed control tissue including lamina propria in five, submucosa in two, and a lymphoid follicle in one. Tissue was cut out of the respective paraffin block with a razor, dewaxed in chloroform, rinsed in absolute alcohol, dehydrated with dimethylformamide, and embedded in LR White resin with $0.5 \%$ benzoin photoinitiator (TAAB Laboratory Equipment Ltd, Reading, United Kingdom) cured by ultraviolet light, as described previously. ${ }^{10}$ Ultrathin $(70-80 \mathrm{~nm})$ sections were cut and picked up on uncoated 200 or 300 mesh nickel grids (Agar Scientific Ltd, Stanstead, United Kingdom).

IMMUNOGOLD STAINING

Immunogold staining was carried out as described previously ${ }^{10}$ using a primary polyclonal antibody specific for the measles virus nucleocapsid protein. The controls for antibody specificity and optimal conditions for reaction are described in detail elsewhere ${ }^{10}$ For each tissue, sections adjacent to those treated with the primary antibody were placed on drops of $0.1 \%$ bovine serum albumin/ phosphate buffered saline to act as negative controls. In order to minimise variation in staining, the protocol was strictly adhered to throughout: the same batches of primary antibody and gold conjugated secondary antibody were used throughout, and sections were cut on the same day as staining was performed to reduce the potential effects of storage. In order to check for staining variation, positive control (SSPE) sections were stained on each occasion that the primary antibody dilution was prepared. Grids were examined on a Philips 301 transmission electron microscope.

\section{GOLD GRAIN QUANTIFICATION FOR STATISTICAL} ANALYSIS

The number of $10 \mathrm{~nm}$ conjugated gold grains per unit cell nucleus area (defined as the fieldof-view through the binocular focusing aid on the microscope at $\times 40000$ magnification) were counted. Stained sections were randomised, nuclei from cells in control tissues were selected for comparison at random, and gold grains counted. To control for variation in gold grain density from grid to grid within the same case, two sections per case were included in the data analysis. Each area was sectioned at least $50 \mu \mathrm{m}$ deeper in the tissue, so that each cell counted was different. Ten counts (five cytoplasmic, five nuclear) were taken of 20 separate cells per tissue area. This allowed most of the area of each cell section to be counted accurately as $10 \mathrm{~nm}$ gold grains were easily visible at $\times 40000$ magnification. The counts were added to give a single value for each cell nucleus and each cell cytoplasm. Background correction was calculated by subtracting the mean counts of adjacent sections treated without the primary antibody from each corresponding primary antibody treated section data point. This procedure gave rise to some negative values which were classed as zero. Fractional values were kept in the analyses as the counts were per unit area, and they can be used in comparison between groups measured in the same way.

The area on the field-of-view through the transmission electron microscope focusing aid at $\times 40000$ magnification was measured using a catalase crystal grid (Agar Scientific). Three measurements of the diameter for each crystal plane were averaged, the actual diameter being the mean of these measurements. The area was 

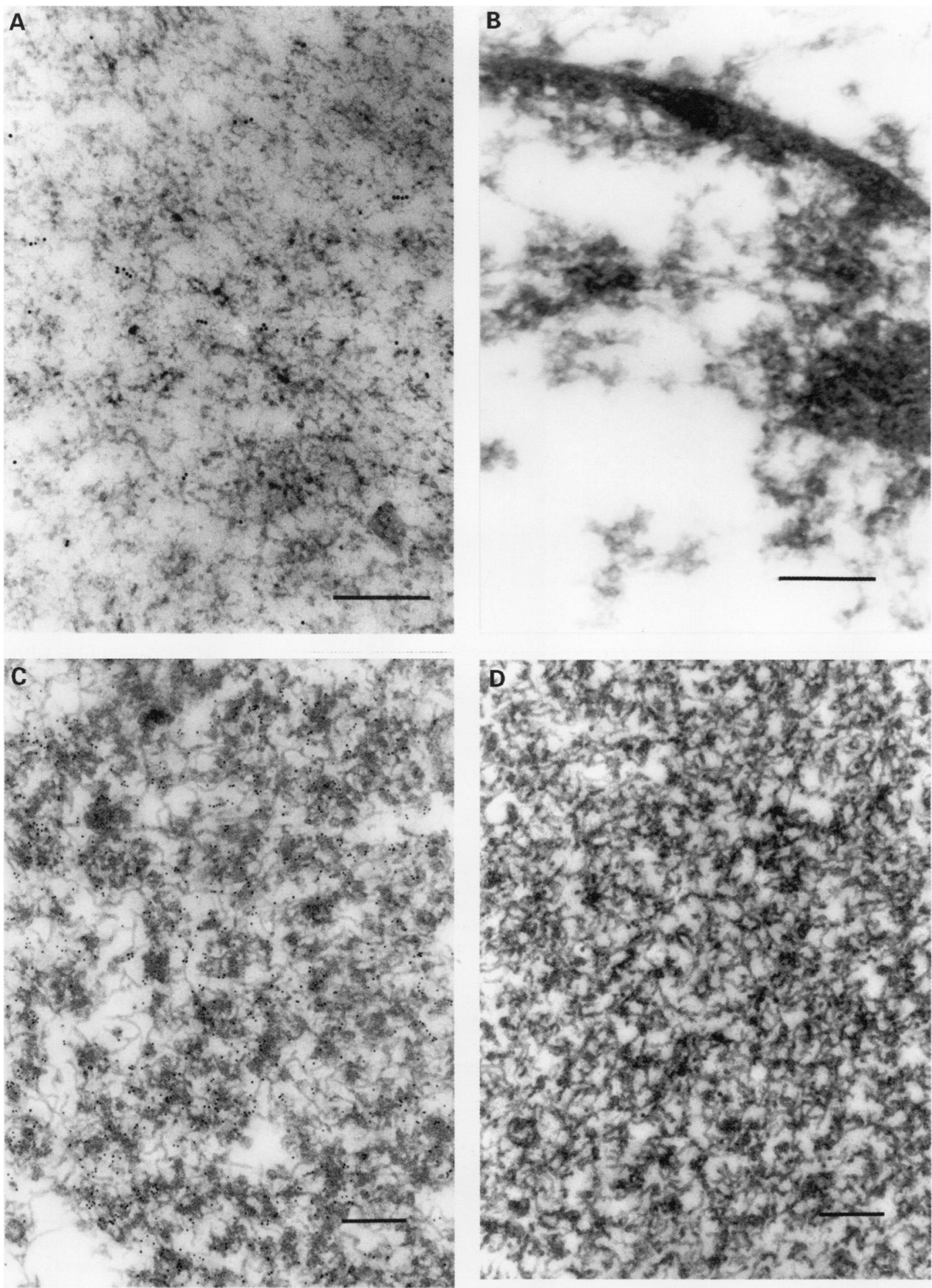

Figure 1 Electron micrographs of tissue sections from a patient with Crohn's disease $(A, B)$ and a patient with subacute sclerosing panencepalitis $(C, D)$. (A) Positively staining cell in a Crohn's granuloma: doublets and chains of gold particles are attached to nuclear tubular structures similar to those found in SSPE $(C)$. (B) Portion of a nucleus from an adjacent section to that in $(A)$, processed without the primary measles antibody. (C) Positively stained nucleus in brain tissue from a patient with SSPE. The section is from a heavily stained cell, doublets and chains of gold particles are attached to tubular structures in the nucleus (arrow). (D) The same cell as in (C) from an adjacent section treated without the primary measles antibody. All bars are $250 \mathrm{~nm}$.

calculated as $22.48 \mu \mathrm{m}^{2}$. The corrected gold grain count values (per $\mu \mathrm{m}^{2}$ ) were calculated by dividing the summated background counts by $112.4(5 \times 22.48)$ and are given in table 1 .

The Wilcoxon Mann-Whitney U test was used in all cases as the data were not normally distributed. To test for significant presence of measles virus antigen, Crohn's granulomas were tested against SSPE and negative controls-tuberculous lymphadenitis granulomas, intestinal ischaemia, ulcerative colitis, and non-granulomatous areas of Crohn's cases. Analysis and the production of a Box and Whisker chart were conducted on Microsoft Excel spreadsheet using the Astute Add-in (DDU software, University of Leeds, Yorkshire, United Kingdom).

Results

In Crohn's disease, eight of nine foci of granulomatous inflammation but none of four foci of non-specific mucosal inflammation were posi- 


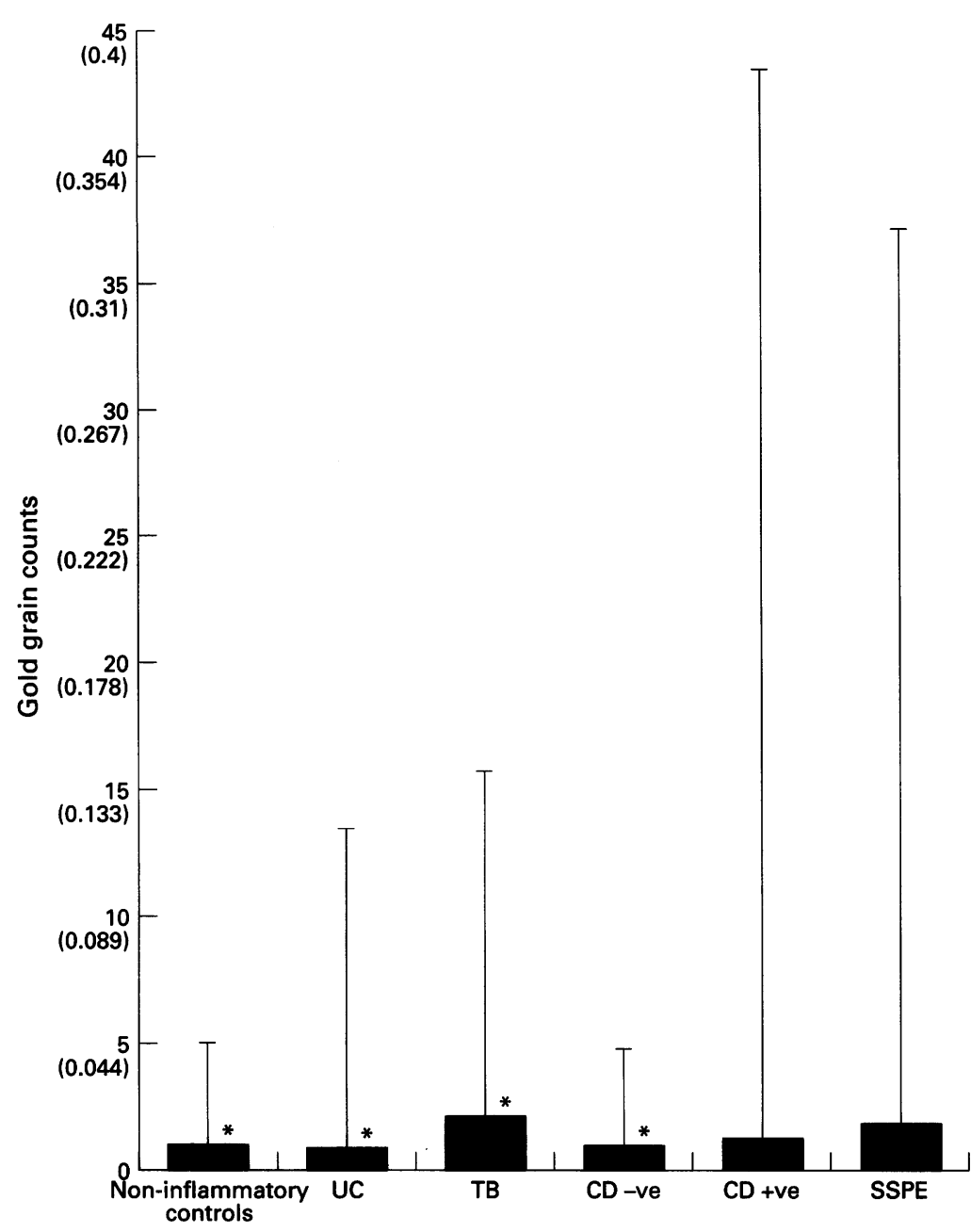

Figure 2 Box and Whisker plot giving the interquartile ranges and maxima for each group. The Wilcoxon Mann-Whitney U test was used to test data higher in value than the non-inflamed controls from each positively stained tissue against data from the known measles positive SSPE tissue. * Statistically significant difference in gold grain count data from the known measles virus infected SSPE case $(p<0.05)$. The maxima and minima are shown as a thin line, with the upper and lower percentiles as the upper and lower limits of the boxes. UC, ulcerative colitis; TB, tuberculous lymphadenitis; $C D-v e$,

non-granulomatous areas of Crohn's disease; CD +ve, Crohn's disease granulomas; SSPE, measles positive control.

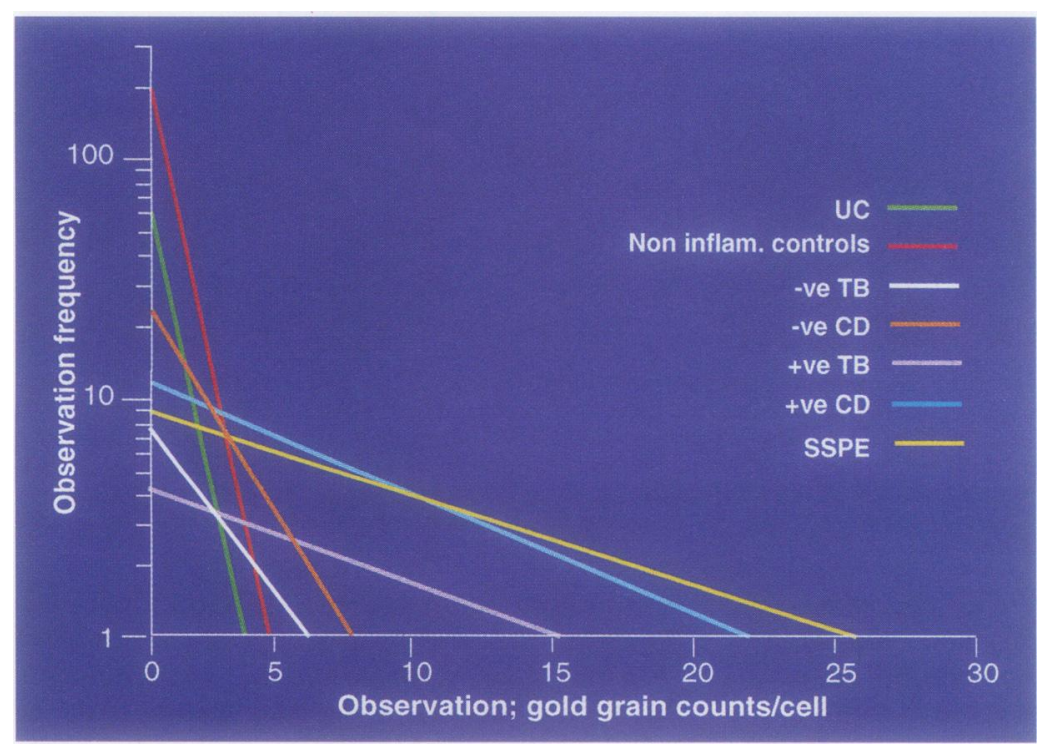

Figure 3 Values for background corrected gold grain counts per unit cell nucleus area plotted against frequency of observation on a logarithmic scale and displayed as the line-of-best-fit. The presence of gold grains was not normally distributed and skewed such that the majority of cells contained very few gold grains in all groups. In both Crohn's granulomas and SSPE, however, a small proportion of cells contained high levels of signal. non-inflam.contols, non-inflamed controls; UC, ulcerative colitis; TB, tuberculous lymphadenitis; $C D-v e$, non-granulomatous areas of Crohn's disease; $C D+v e$, Crohn's disease granulomas; SSPE, measles positive control. tive for measles virus (fig $1 \mathrm{~A}$ and $1 \mathrm{~B}$ ). One of five ulcerative colitis specimens, one of eight specimens of tuberculous lymphadenitis, and the single case of SSPE (fig $1 \mathrm{C}$ and 1D) were also positive. All sections treated without the primary antibody had extremely low levels of signal (fewer than two gold grains per field-ofview at $\times 40000$ magnification $=<0.018 / \mu \mathrm{m}^{2}$ ), usually being completely free from gold staining. Positive staining was characterised by predominantly intranuclear clusters of gold grains. In addition, positively staining nuclei in both SSPE and Crohn's disease exhibited peripheral margination of nuclear chromatin-a characteristic feature of cells persistently infected with measles virus. ${ }^{11}$ Gold particles arranged in doublets and chains were frequently observed, as described previously. ${ }^{10}$ Despite suboptimal preservation of archival, formalin fixed tissues, the identification of virus-like particles was possible albeit rarely, within the Crohn's granuloma (fig 1A). Where giant cells were present within Crohn's granulomas, positively staining cells were often clustered around the giant cell which was itself usually negative: one giant cell exhibited positive staining within cytoplasmic vacuoles.

For the purposes of quantification, 26160 counts of gold grains per unit cell area were made and analysed: this comprised 2616 cells (five nuclear and five cytoplasmic counts from each) on 114 grids of 29 tissue areas from 25 cases (three consecutive cases of Crohn's disease where granulomas were targeted and three where non-granulomatous areas were targeted; one case of Crohn's disease where both a granulomatous and non-granulomatous area was targeted in the same patient; and positive and negative controls).

Nuclear count values, including medians, interquartile ranges, and maxima of each disease group are given in table 1 and fig 2 . No significant levels of staining were found in the cytoplasm of cells in any tissue other than one giant cell from a total of three giant cells examined in three separate Crohn's disease cases. In all Crohn's granulomas analysed, a minority (approximately 15\%) of cells was positive for measles virus nucleocaspid protein. No positively staining cells were identified within four areas of non-granulomatous inflammation in Crohn's disease tissue. A similar distribution of staining was found in the single SSPE tissue analysed. In addition, there was no significant variation in the counts for successive SSPE sections stained with each primary antibody dilution. The distribution of staining gave rise to interquartile ranges that were similar for all cases, with Crohn's granulomas, SSPE, and the single positive tuberculous lymphadenitis case having maxima that were markedly higher than the control cases.

The frequency distribution fitted a negative exponential model. On a logged frequency graph, the lines-of-best-fit for nuclear count values versus frequency of observation were remarkably similar for granulomatous areas of Crohn's disease and SSPE tissue, and different from all other groups (fig 3-produced using Cricket graph for Windows (Computer Associ- 
ates, Slough, Berkshire, United Kingdom, and Microsoft Corporation, Seattle, Washington, USA)). Conversely, the lines-of-best-fit for non-granulomatous areas of Crohn's disease tissue corresponded closely with those for control, ulcerative colitis and tuberculous lymphadenitis data (fig 3).

The gradients of the lines-of-best-fit for control cases are: ulcerative colitis, -0.32 ; noninflamed controls, -0.47 ; eight of nine tuberculous lymphadenitis cases (measles negative), -0.217 ; and Crohn's disease (nongranulomatous areas), -0.47 . The gradients for measles positive Crohn's disease cases (granulomatous areas) cases and the SSPE case are at least an order of magnitude lower $(-0.05$ and -0.04 , respectively). The single measles positive case of tuberculous lymphadenitis gave a similar staining pattern (gradient -0.05) to granulomatous Crohn's disease, albeit at an overall lower level of signal.

The immunogold technique used in the present study stains only antigenic binding sites on the surface of sections and is, therefore, not necessarily a true reflection of the amount of antigen present. However, the technique does allow comparison of data between cases treated in the same way. The Kruskal-Wallis one way ANOVA demonstrated a highly significant difference $(p<0.0001)$ in variance of nuclear gold grain counts within the cases. To test the hypothesis that measles virus antigen was associated with Crohn's disease, the Wilcoxon Mann-Whitney $U$ test was used to compare data from positively stained cells in measles positive tissue areas: the one positive ulcerative colitis case, the one positive tuberculous lymphadenitis case, four Crohn's disease granulomas from separate cases, and the one SSPE case. The data for SSPE and four Crohn's disease granulomas were tested, independently, against four areas of nongranulomatous Crohn's disease tissue from individual cases. In addition, data from a nongranulomatous area and a granulomatous area of the same tissue were tested.

The Wilcoxon Mann-Whitney U test demonstrated no significant difference between the gold grain counts for SSPE and the four granulomatous areas of Crohn's disease $(p>0.1)$. The single positive ulcerative colitis and tuberculous lymphadenitis tissues had significantly lower counts when tested against SSPE ( $p<0.001, p=0.027$, respectively). There was no significant difference between the gold grain counts for Crohn's disease granulomas and SSPE $(p>0.1)$. The gold grain counts for SSPE and granulomatous areas of Crohn's disease tissue were significantly greater when tested against nongranulomatous areas of Crohn's disease $(p=0.0006)$. Granulomatous areas also had a significantly greater level of staining than nongranulomatous areas in the same case of Crohn's disease $(p<0.001)$.

\section{Discussion}

Measles virus nucleocaspid protein was present within diseased tissue in the majority of Crohn's disease cases examined. This finding, supported by the localised distribution of positively stained cells within Crohn's disease granulomas, and the similar distribution of measles antigen in SSPE, suggests that the measles virus may have a role in the aetiology of Crohn's disease. However, the technique used was limited to the intensive study of relatively small numbers of tissues, and a wider-perhaps molecular epidemiological study-would be appropriate before further conclusions can be made.

Previous studies have used in situ hybridisation, ${ }^{5}$ immunofluorescence, ${ }^{6}$ and immunogold electron microscopy ${ }^{10}$ to demonstrate the presence of measles virus in intestinal tissues from inflammatory bowel disease patients. The measurements used in the present study enabled an assessment of the distribution of measles positive cells in the tissue areas examined, and highlighted a striking similarity between Crohn's disease and a persistent measles virus infection of the brain (SSPE). The data suggest that measles virus antigen is localised within Crohn's disease tissue to foci of granulomatous inflammation. Furthermore, the antigen appeared to be present in only a small percentage of cells examined, even where granulomas were specifically targeted. Such a low abundance of virus may make it difficult to detect by-for example, reverse transcription polymerase chain reaction assay (RT-PCR). ${ }^{12}$

Recent work from Japan has provided further evidence for the presence of measles virus in Crohn's granulomas. ${ }^{6}$ Miyamoto et al showed a strong affinity of a monoclonal antibody against the measles virus matrix protein for leucocytes around the giant cells of Crohn's granulomas by immunofluorescence, which was not seen in controls. In the present study the cytoplasm of one of three giant cells examined from three different cases was positive for measles antigen. The presence of gold grains in the vacuoles of this giant cell may indicate a situation similar to that observed during HIV associated syncytium formation, where viral budding occurs in the giant cell vacuoles. ${ }^{13}$

Recent studies of postmortem brain specimens, using RT-PCR, have shown that measles virus persists commonly in cerebral tissues that are otherwise normal. ${ }^{14}$ The authors concluded that measles virus persistence was a frequent occurrence, whereas delayed disease associated with persistent cerebral infection was rare. The finding of measles virus in a minority of control intestinal tissues is perhaps, therefore, not surprising. Absence of gold staining in seven of eight tuberculous granulomas suggests that measles virus nucleocaspid protein antigen is not associated simply with a granulomatous inflammation. However, the finding of positive cells in one tuberculosis sample (despite the lack of significance by Wilcoxon MannWhitney $U$ test) raises the possibility that measles virus might persist in immune cells that have been recruited to foci of granulomatous inflammation, induced by other agents. Furthermore, measles virus is profoundly immunosuppressive both during and after the acute infection ${ }^{15}{ }^{16}$ : persistent infection of macro- 
phages may render them functionally different and, perhaps, precursors of an acquired chronic granulomatous disease. Further work is underway to characterise the nature of the persistently infected cells by double immunogold labelling.

Persistent measles virus infection has recently been implicated in the aetiology of ulcerative colitis, ${ }^{8}$ rekindling the hypothesis that inflammatory bowel disease is a spectrum of disease with a common cause but a differing immunophenotype. We could not provide evidence for this hypothesis in the present study. However, the specific localisation of the virus to discrete foci of granulomatous inflammation in Crohn's disease, against a background of diffuse non-specific inflammation containing no detectable virus, permits targeting within Crohn's tissues. This is not the case in ulcerative colitis, making the potential for sampling error much greater. Until the primary site of antigen presentation can be identified and targeted in ulcerative colitis, this issue is unlikely to be resolved.

In summary, this quantitative immunogold electron microscopy study localised the measles virus nucleocaspid protein antigen to areas of granulomatous inflammation in Crohn's disease. The distribution of staining and the associated pathological changes in infected nuclei were virtually identical to those seen in SSPE, a persistent measles virus infection of the brain, suggesting a similar aetiology for Crohn's disease.

We gratefully acknowledge Dr A M Seddon (Kingston University, Kingston, Surrey) and Dr D H Humber (University of Eas London, London) for assistance with the statistical analysis. We also thank Professor R M Pittilo (Kingston University and S Georges Hospital Medical School, London) for his support of this work. The measles virus nucleocaspid protein antibody was a gift from J Stephenson and A Warnes, CAMR, Porton Down.

1 Knutson H, Lunderquist A, Lunderquist A. Vascular changes in Crohn's disease. Am $\mathcal{f}$ Roentgenol 1968; 103:380-5.

2 Wakefield AJ, Sawyerr AM, Dhillon AP, Pittilo RM, Rowles PM, Lewis AAM, et al. Pathogenesis of Crohn's disease: multifocal gastrointestinal infarction. Lancet 1989;ii: 105762.

3 Wakefield AJ, Sankey EA, Dhillon AP, Sawyerr AM, More $\mathrm{L}$, Sim R, et al. Granulomatous vasculitis in Crohn's disease. Gastroenterology 1991;100:1279-87.

4 More L, Sim R, Hudson M, Dhillon AP, Pounder RE Wakefield AJ. Immunohistochemical study of tissue factor expression in normal intestine and idiopathic inflammatory bowel disease. 7 Clin Pathol 1993;46:703-8.

5 Wakefield AJ, Pittilo RM, Sim R, Cosby SL, Stephenson JR, Dhillon AP, et al. Evidence of persistent measles virus infection in Crohn's disease. F Med Virol 1993;39:345-53.

6 Miyamoto H, Tanaka T, Kitamoto N, Fukada Y, Takashi S Detection of immunoreactive antigen with monoclonal Detection of immunoreactive antigen with monoclonal antibody to measles virus in tissue from patien

7 Ekbom A, Wakefield AJ, Zack M, Adami H-O. Perinatal measles infection and subsequent Crohn's disease. Lancet 1994;344:508-10.

8 Thompson N, Montgomery S, Pounder RE, Wakefield AJ. Is measles vaccination a risk factor for inflammatory bowel disease? Lancet 1995;345:1071-4.

9 Ekbom A, Daszak P, Kraaz W, Wakefield AJ. Crohn's disease following in utero measles virus exposure. Lancet 1996;348: 515-17

10 Lewin J, Dhillon AP, Sim R, Mazure G, Pounder RE, Wakefield AJ. Persistent measles virus infection of the intestine: field AJ. Persistent measles virus infection of the intestine: confirmation by

11 Tellez-nagel I, Harter DH. Subacute sclerosing leucoencephalitis: ultrastructure of intranuclear and intracytoplasmic inclusions. Science 1966;154:899-901.

12 Haea Y, Funakoshi O, Kuroe K, Kanazawa K, Nakajima H, Santo $\mathrm{H}$, et al. Absence of measles viral genomic sequence in intestinal tissues from Crohn's disease by nested PCR Gut 1996;38:211-15.

13 Dowsett AB, Roff MA, Greenaway PJ, Elphick ER, Farrar $\mathrm{GH}$. Syncitia-a major site for the production of human immunodeficiency virus. AIDS 1987;1:147-50.

14 Katayama $\mathrm{K}$, Hotta $\mathrm{H}$, Nishimura A, Tatsuno Y, Homma $M$. Detection of measles virus nucleoprotein mRNA in autopsied brain tissues. $\mathcal{F}$ Gen Virol 1995;76:3201-4

15 Pelton BK, Hylton W, Deman AM. Selective immunosupPelton BK, Hylton W, Deman AM. Selective immunosuppressive effects

16 Cooradia HM, Wesley A, Henderson LG, Brain P, Vos GH, Hallet AF. Alteration in immune responsiveness in acute measles virus infection and chronic post-measles chest disease. Int Arch Allerg Immunol 1978;56:14-23. 